\title{
History and the Problem of Bibliography
}

$\mathrm{T}^{\mathrm{N}}$ its broad sense history is the realm of 1 recorded mind. Informing man about man, history affords a prospect of future consequences. Society-past, present, and future-here finds public judgment, and the people of an age and place learn their failures and their promise from this interpreter's voice. The ancients seemed to know the vastness of the historical matrix, sometimes perhaps better than "we. "History," wrote Polybius, "is now an organic whole. The affairs of Italy and Africa are intermingled with those of Asia and Greece, and all move to one end."

Our own century frankly calls itself the age of "global" war. So it will be remembered by our children's children and theirs, for countless generations. Although we do not have the identical "one end" that Polybius envisioned, the interrelation of peoples, of regions, and of the realm of mind is truly as he intimated it would be. The history of recent civilization, including advances in knowledge and the increase of "documentation" (in the French sense) demonstrates that the web of culture is indeed tightly woven. Dramatic revolutions in science or technology, in political action or in the literature of imagination, hardly constitute isolable phenomena. Correlative, sudden, or gradual changes in the remainder of the continuum indicate that society, although it may not be "organic," is in some sense a totality whose component parts are separable only for

1 Much of the composition of this article is the work of Adrienne Koch. theoretical conventence or for immediate use and action.

Bacon's ability to classify recorded knowledge in terms of three great "faculties" of the human mind-memory, reason, and imagination-was possible, even in his time, only with strain and largely because of the lack of knowledge of psychological operations. Those who used the Baconian classification as the guide to the organization of libraries were already finding it unworkable in the eighteenth century, since the presses had even then multiplied the products of written expression beyond an easily manageable quantity. Today the most elaborate classification, carried to a fine degree of subdivision, is at best a practical compromise, actually out of date to some small degree in the very moment of its conception. Intense specialization in professional inquiry may continue to be a modern practice for certain scholars and scientists for years to come; but for the realities of subject matter relationship, the "fringes," as William James would have said, are thick and they involve the separate subject matters in a public embrace destructive of highly technical privacy. This condition complicates the problems confronting bibliographers and makes bibliography peculiarly dependent upon the historical contingencies that determine the character of an age.

Bibliography derives its chief functions from the omnivorous demands of historiographers. Even so-called "current" bibliography is history-young and fresh history 
-suited to the restless acquisition of further knowledge. Bibliography is thus a handmaiden to cultural growth, a handmaiden now seriously overworked, taxed by the enormity of society's published records increasing with the years. The older society becomes, the more it "grows up," the harder it is for bibliographical controls to maintain their hold over the voluminous outpourings of the mind and spirit, externalized not only in print but in the multiple forms of duplication, photography, etc., spawned by the technologists of our times. In the familiar battle cry of one of the most imaginative librarians in the country: "...We seem to be fast coming to the day when, unless it is afforded the most expert sort of bibliographical service possible, civilization may die of suffocation, choked by its own plethora of print."

\section{Improve Bibliographical Activity}

The psychological attack made by these ever increasing intellectual materials has depressed many a deserving scholar. It is my thesis that to prevent that fatal depression from becoming an enervating habit, deeply engrained in the culture of the future, we must improve the scope and quality of American bibliographical activity. I think the assumption of bibliographical leadership on a cooperative basis by the United States, Great Britain, and Russia -the only great powers possessing the necessary resources to fulfil the ensuing obligations-is practically imperative. For whatever German proficiency in bibliographical enterprises may have been (and everyone knows that German superiority in the organization of scientific literature was not only commendable in itself but probably had something to do with their genius in the pure and applied sciences), there is no chance that Germany or any European or Asiatic country will have the confidence or the funds with which to assume leadership again. It is clearly the responsibility of the three great Western powers from now on. The future availability of knowledge for the whole world is therefore bound up with the bibliographical planning we do. In this area American librarians particularly must henceforth live up to the exacting demands of statesmanship. To fail here means not only a vital deficiency in the sources of information which we can put at the disposal of our own scholars and general readers, it means the retardation of the role of America as a great agent of international understanding and progress. And this role, as I see it, is not too distantly connected with the keeping of peace among the united or dissident nations of the future.

\section{Failures in Our Recent Past}

The "ultima ratio regum" through which we have just passed and in which the peacetime intellectual activities of knowledge were sharply curtailed, save as they were themselves made elements of "total war," brought to the surface many of our ominous failings in the organization of knowledge. Government agencies, pressed for time and often scrambled into an "organization" overnight, had to construct makeshift bibliographies of research materials in fields that were directly related to the activities of our land, air, and naval arms. Often the gaps in our prepared descriptions and locations of materials caused the most costly delays in strategy, in direct military operations, and in home front planning. One small illustration: During the war several groups in the Department of Agriculture, in the Navy, and a Congressional Committee were interested in investigating new uses for milkweed floss. They were unable to reach a decision until the Department of Agriculture Library published its excellent bibliography summarizing the his- 
tory of the literature pertaining to milkweed floss. Once the bibliography was available, the decision was immediately reached, and milkweed floss proved to be an important substitute for kapok in life preservers.

Insufficient information on the enemy country, Japan, and on all the Asiatic countries included in what the Japanese called the "Greater East Asia Co-Prosperity Sphere" was a different type of shortcoming in our bibliographical program. There was virtually nothing reliable in this fieldneither adequate lists, nor abstracts, nor subject bibliographies. Unfortunately even the material was lacking, our files of Japanese scientific periodicals being meager and incomplete. Therefore, the situation was not basically remedied while the war continued.

But it would be absurd to think of the war as the sole context in which bibliographical failures matter or show up. The fact that most bibliographical ventures, including those of the greatest usefulness, were business ventures or privately endowed, made them undependable in publication dates, duplicative of the contents of other services, and sometimes tragically transitory. One of the best examples of a bibliography which filled an important need is the Social Science Abstracts. But I need only recall to you the dates of its birth and demise (I929 and I932) to make it obvious that its duration hardly sufficed to fulfil the expectation it had succeeded in arousing in the public. Another serious failure was the discontinuance, in I914, of the International Catalogue of Scientific Literature which had been founded only thirteen years earlier.

These particular bibliographical projects were only small segments of a large problem. Stating it in general terms, bibliographical controls have not approached close enough to the ideal of continuous coverage of everything that is being published annually in the countries of the world. Not even the entirety of American output has found proper recording, since the C.B.I. fails to include many private and research publications and excludes all government published books and pamphlets. Of equal gravity is the failure to have indicated the location of all the materials held by libraries in this and other countries. Nor have we penetrated the wall of sheer quantity to carve out the evaluative bibliographies-bibliographies supplied when necessary with historical surveys and annotations of an evaluative and critical sort that might heighten the accurate selection of literature by the overburdened scholars, thereby hastening their research to its fruition.

\section{Steps in the Right Direction}

Two projects, recently proposed, seem to us at the Library of Congress to be moving in the right direction. I refer to the proposed "International Index of Scientific and Technical Literature" and the initial studies of the Joint Committee on Indexing and Abstracting in the Major Fields of Research. It is not yet certain whether these proposals will eventuate in satisfactory action, but, clearly, coverage of every important field is essential. A rational plan to ensure that there will be no important lacunae is the first big task on the agenda of libraries and scholarly societies in this country.

Such a plan would recognize that bibliographical controls must operate on two levels-library control and subject control. Advances on the two levels are usually interrelated. Subject control concerns special bibliographies, and I should like to comment that there is a limiting factor here of the kind of researcher for whom the bibliography is prepared. Some good re- 
searchers are unwilling to rely on another person's or institution's bibliography or will do so only for certain areas of knowledge. But all readers (including good researchers) want bibliographies to help eliminate the clutter of out-dated, incompetent, and trivial publications. Subject control must, as a minimum, provide this.

In library control we are confronted with an over-all problem. The objectives here must be to ensure comprehensive and continuous coverage and to employ all the aids of cooperative acquisitions policies, national commercial book indexes and government publications indexes, and "complete" union catalogs. Retrospective library lists enumerating holdings are also important in this connection. Admittedly, this is the far-off, long-range ideal. I do not think that if we were somehow mysteriously endowed with ample funds for bibliographical ventures, we would at this point be ready to set up the most reasonable, economical, and farsighted program. Now is the time for $e x$ ploratory studies, based on sound philosophy and backed by the most careful statistical and scientific data and investigations.

\section{Growth of Book Production}

To show you the unhealthy state of library statistics (and, for a basic picture, statistics have considerable bearing on the program we construct for bibliography), let me simply ask the reasonable question of how rapidly the book production of this country and of the world is growing? Is there any librarian in the country who can answer that question? Practitioners of library "science" ought to have some fairly respectable quantitative hypothesis about the books they believe are in existence and the amount they roughly calculate they will have to provide for in their libraries and in their bibliographical reports and journals, before they can plan intelligently for the future. I will only call your attention to the figures given in Union Catalogs in the United States, a book admirable and justified in so many respects that I hope you will not assume that I am putting the blame for our incomplete and inadequate statistics at the door of authors whose primary job was not the analysis of such estimates. But figures are cited and tables reproduced which make little sense from a statistical point of view. We learn, for example, that the United States in 1940 ranked eighth in production of books, while Japan ranked first, Germany second, and France third. These rankings $I$ find curious. Are they reliable statistical findings, based upon a complete count of trade, government, and private press publication of books and pamphlets in every country of the world? Or are they a hodgepodge, as the sources upon which the figures are based so eloquently indicate, of partial listings, inconsistent definitions of what constitutes a "book" or a monograph or a pamphlet? In short, are we adding up figures and deriving comparative ranks from totals which have not been subjected to proper statistical scrutiny to determine whether they are based upon homogeneous units? Besides, I have a hunch that things have changed pretty radically in the past six years and that the United States at the present time ranks higher in world book production. It seems worth while for us to investigate so that we may know if this is true. And finally, of the total number of books published since the beginning of printing, it is estimated that U.S. libraries hold about two-thirds of world library resourcesabout ten million titles. As the authors justly comment, the assertion that we hold two-thirds of total resources must be taken with "reservations," principally the incompleteness of book production statistics in general and the "padding of American li- 
brary holdings with manuscript and minor printed materials that do not find their way into production figures." In addition, most of these estimates fail to go beyond works in the Latin alphabet. It seems obvious to me that what is required is a thorough statistical survey, giving us a more reliable quantitative picture of where we stand with respect to the past, present, and future of books, pamphlets, newspapers, and even smaller pieces. Perhaps then it will be possible to do more than match wits about whether college libraries double every thirteen, fifteen, or sixteen years and grow in "geometric" rather than "arithmetic" progression.

\section{Proposed Bibliographical Planning Project}

Investigations like these, and many others of a more cultural character, can perhaps best be conducted from a bibliographical center. In our present estimates submitted to Congress we have asked for funds to inaugurate a bibliographic planning project, a pilot unit to analyze the problems of bibliography and make preliminary recommendations, indicating priorities among the most important tasks. When this pilot project has contributed its reports, the next steps can be charted with more realistic detail. It is hoped that by that time we can expect informed decisions on how to make available knowledge of what exists in print.

I have already referred to our present ignorance about what is being published by the governments of the world, by the book trade, and by private publishers. It is likely that we at the Library of Congress may be able to spearhead the movement in this direction; but, unless an international organization like the United Nations Educational, Scientific, and Cultural Organization devotes part of its educational services to the bibliographical listing of documentary materials, it is dubious whether significant ad- vance can be made in this total long-range job. It is obvious that knowledge will not be diffused or advansed to an optimum degree unless we have arcess to books. This means that there must be listed at least one copy of every book published, for, without complete listing, books cannot be rationally acquired by libraries. Is it necessary to add that the whole enterprise would be useless if it excluded the listing of the contents of periodicals as well as books? In the sciences particularly the absence of periodicals would greatly lessen the value of subject lists of "literature" in a field. The cooperative practice of exchanging books and pamphlets, particularly those issued by the government, would be a concomitant of adequate bibliography on the library level.

Let us anticipate that the bibliographical surveys take these initial hurdles easily. Then I would suppose that the next type of inquiry would concern itself with the major levels of organization in bibliography. The purpose of reviewing the different levels individually is to ascertain the urgency of initiating new publications in different categories. What will we need in listing? In abstracting? In review journals? In subject literature reports? Obviously not every subject matter can exert the same just claim about the urgency of inaugurating review journals.

\section{A Few Achievements for the Score}

The Library of Congress has made considerable progress in bibliographic activities within the last few years. First there is the union catalog. I will not review the history of the expansion of our union catalog, but it now has under listing and locational control about three-fourths of the total number of titles held by libraries in the United States. It may prove necessary to develop classed union catalogs, and we have already started to build the nuclei of union catalogs for 
works in the non-Latin alphabets. Second, there is bibliographical synthesis on the highest level being carried on by the Legislative Reference Service and by sections on the Public Reference Service. I know from library mail and from personal conversation that many newspaper and magazine editors, research groups, and individual scholars would be grateful if the bibliographical services undertaken for Congress were regularly made available to consumers on the outside. These groups of consumers are the intellectual advance guard of this country, and keeping them informed is a vital part of the job of democratic political education. I have on my desk now a memo from the library of one of the most influential magazine combines in the country saying that the reports prepared by the Legislative Reference Service are "splendid works" and, though they are prepared for the use of Congress, it would be a great aid to receive them or at least to receive a list of the reports prepared in the Library of Congress; and similar comments are made about the Public Affairs Bulletins.

\section{Alternatives}

Perhaps citing bibliographical examples from the field of politics, history, and the social sciences in general is instructive about the direction of development for a subject bibliographical program. I feel confident that subject bibliographies in the field of the sciences will be given extensive treatment by government research, scientific groups, and business firms throughout the country, for funds are easily forthcoming for purposes of scientific research. Librarians should perhaps give more intensive attention to the problem of bibliography in the humanities and social sciences.

The question of bibliographical planning is one which can be surveyed only in the most general terms, without raising the fundamental question of financing. In theory, the Library of Congress and probably libraries throughout the world recognize that their bibliographical activities depend upon the closest cooperation with the professional experts in every field, who are capable of interpreting changes and of informing bibliographers about changing needs and, frequently, about the changing terminology of their respective subjects. Whether the Library of Congress should perform a significant role of national coordination and organization of bibliographical projects, depends to a great extent upon the kind of government subsidy or foundation support the learned societies and professional groups are able to arrange for. It seems safe to assume that the services and resources of the Library of Congress will doubtless be enlisted, and it is more than likely that it will be expected to act as a clearing house of bibliographical information for the entire country and in some cases for the entire world. But certainly there is little to be gained by thinking in terms of a high concentration of bibliographical activity in any one center.

Differences of viewpoint already exist, not only inside the Library of Congress, but throughout the world, about the best approach to ensure the establishment of adequate bibliographical control over the world's literature. I am sanguine that these differences will be immaterial in the long run, since they tend to run to extremes as opposed viewpoints often do. One theory is that only the "selective" evaluative bibliography is worth sponsoring; another, that only the complete listing of works provides the needed base for intellectual sorties and that the scholars can concoct bibliographies to suit their own needs. I am at a loss to see why there must be war about these issues, since it seems plain to me that both types of activity are absolutely obligatory 
and indeed mutually complementary. The trick is to find the comprehensive pattern which will satisfy the needs of all significant groups who have occasion to approach recorded knowledge with important questions.

\section{History Presents New Issues}

In a special sense, history enters the domain of bibliography at the particular juncture of our present development. The exigencies of the war placed peculiar emphasis upon the "area" or regional approach. By and large, library practice in America had been structurally determined in terms of functional classifications. The functional versus the regional remains a vexed question, affecting the development of bibliographical programs. Yet, in principle, it seems sensible to me to make a distinction between the usefulness of regional organization for bibliographers on a purely factual or event level of interest, and of functional organization in terms of broader theoretic and analytic interests. Thus the geography, economic organization, political events, customs, and living conditions of Northern Borneo can be successfully treated on an area basis, although only up to a certain point. But questions arising about geographical theories, economic theories, political hypotheses and principles, and the broader issues in any science, as in philosophy and art, involve a typical viewpoint which is nonregional, nonnational, but properly international, conceptual, and testable by the usual canons of evidence to determine adequacy and inadequacy, rather than by place of origin or existence.

Separate collections and separate library sections-like those devoted to Slavic studies, to the Far East, or our Hispanic Foundation-can sponsor a certain kind of regional bibliography, like the Handbook of Latin American Studies. But a bibliography like the "History of Science and
Civilization" contained in Isis performs a very different function and can have regional categories introduced only on a minor, subdivisional basis. Those who work with the history of ideas are primarily interested in themes, or concepts, or subject matter, if you prefer; and the very broadness of the Isis classification, straddling the fields of history of science, philosophy, and civilization is and must be characteristic of bibliographies organized to achieve synthesis. Only experts in the literature of these fields can perform the selection and authenticate the judgments implicit in "broad" bibliographies of this order. Whether the experts put in an eight-hour day as members of library staffs or show their virtuosity on the outside in universities or as members of professional groups is immaterial. Possibly a better classification than the one in Isis might have been devised- "better" in the sense of aiding the user to find the books he wants in one rather than in any one of three or four categories-had intensive and enlightened library study been an integral part of the professional approach to this complex subject. But the unique service provided by the Isis bibliography nonetheless deserves appreciation.

\section{Other Important Problems}

Other important problems emerge from the historical actualities of the period in which we live. One of these is the inevitable effect of that specialization in knowledge referred to earlier. For we find that we must concentrate more than ever before on securing more adequate (meaning more comprehensive, standardized, and exhaustive) finding lists. This is work begun by the National Union Catalog and by publications like the Union List of Serials and American Newspapers, $1821-1936$. Yet, at the same time there is an equally pressing necessity to circumvent the general 
character of cataloging and to provide lists with some "personality" of their own, by which I mean special lists and other bibliographies constructed for rather well-defined groups whose particular interests can be anticipated. I am emphasizing that the historic juncture in which we now find ourselves no longer permits us leeway to debate whether we shall aim at more universality or more specialization and individualization. It rather makes it imperative that we become more comprehensive than we ever fancied we would have to be before and, at the very same time, more specialized on both the research and "general reader" levels. If it should turn out that the I.B.M. card can fulfil the promises predicted by those who are now investigating its bibliographical and cataloging potentialities, some of the more sensitive and discriminatory cataloging and bibliographical work may be performed with an economy of human labor.

But specialization places still other burdens upon us; for example, in attempting to control the periodical literature of the sciences and the humanities. Some years before the war an American expert on Chinese civilization decided that the important periodical $T^{\prime}$ oung $P a o$ required indexing, in order that the subjects discussed in its articles, and even in the weightier footnotes documenting certain articles, be listed for the benefit of students and experts in Oriental civilization. Often titles of articles and the authors' names are insufficient to identify the contributions to knowledge they may contain. At the time the proposal was made, money was not available to finance the project; more recently, it has been revived by the American Council of Learned Societies and is being carried out at the University of Chicago.

\section{Unrealistic Objection}

I have purposely chosen this illustration because it may draw someone's objection that this is indeed descending to a fine level in the subject matter direction and that it belongs wholly to the scholars! However, such a position is as unrealistic as it is unimaginative: unrealistic, because even if university faculties wanted the onerous additional labor of supervising and editing indexing projects for serial publications and were willing to assume such new assignments without extra pay, they probably would not be able to command the right number and quality of library assistants. And they might not always undertake the project at the right time nor be prepared to see it through on a systematic year-by-year basis. Shall we try to pass the buck to professional societies? Are they not frequently straitened for funds and are they not in many cases composed of the same overworked instructors and professors whose difficulties in assuming this new responsibility we have just mentioned? And are their interests too individualistic to sustain such group planning and effort? Obviously, the organized profession in each field should give counsel and should participate in both the over-all rational program of bibliography and in the special bibliographies to be undertaken in separate fields. But nothing less will do to solve this problem than (I) a dependable, ample endowment to be routed, as the case may be, to the Library of Congress, other libraries, and professional groups, depending upon the program agreed upon by all qualified interests; and (2) a systematic procedure, suggested by a top planning group responsible for a cooperative national (or world) bibliographical program, perhaps centered for clearing house purposes in one or several great research libraries.

But history is not yet done with bibliographers. For, to cap the climax, the past (with which the naive believe they are done, for once and all, after it has been "put" into history books) constantly returns to 
upset finished bibliographies. Thirty years ago, if we had consulted a bibliography of ancient Chinese history, we would have found mention of certain "emperors" of the period of about 2200 B.C. Recent research has shown that in fact these "emperors" were inventions of a later date. Bibliographies of ancient Chinese history will now have to follow the lead of the reinterpreted "past" and doubtless will need revision after revision as the past continues to cause a row in the "present."

\section{The Present and Future}

If the past is troublesome, bear in mind that the present and future are even less docile. A few years ago when Princeton's archeological expedition turned up a great cache of Roman mosaics never before viewed by the modern world, the new finds added to the artistic sources of enjoyment, they added to our knowledge of civilization, but they inevitably added too to the workload of the bibliographers of art history! Remember that we are getting to know more and more even about that amorphous period hitherto described as "prehistory." Our microfilming techniques make materials available from the far corners of the earth. Our manuscript sources are constantly swelling the size of library collections. And the enormous quantity of government publications and war records has not begun to be subdued for listing and bibliographical processing.

From inside the libraries themselves comes another type of historical challenge. What major libraries contain is far from known by library patrons. This is true both for general and special book collections and for special forms like manuscripts, sound recordings, photographs, etc. In this field complete bibliographical control is feasible, requiring only adequate staff and time to prepare complete enumerative lists. How important such lists may be, can be shown by the following illustration. An editor was recently preparing a one-volume edition of the political writings of one of our great early presidents. Published sources were used first, and then the question of manuscript collections arose. No professional historians were certain about the location and description of these collections, and when they were finally located (after considerable loss of time) the historical societies and libraries holding them were unable to supply printed lists or typescripts calendaring their collections. For research in American history it is vital that scholars be given these initial aids if they are to do their best work -indeed, if this nation is to learn the accurate story of its own development. Should the day ever arrive when early imprints and manuscripts in this important field are adequately listed and described, we may be saved from the plague of secondary source rewriting of nineteenthcentury American histories.

\section{Question of Distribution}

Extending this criticism further, brings up the inevitable question of the distribution of information and bibliographies by the libraries. If my account of the special sense in which history is forcing our hand, bibliographically, is true, we need a pretty radical revolution in our methods of reaching the public with information. The more the sociologists can learn about special reader group interests, the more obligation we will have to prepare bibliographies suited to reach them with pertinent information. The more our scholars turn to creative historical interpretations, the more need there will be to publish bibliographies suited to their needs-not only locating valuable collections, for instance, but giving them reliable lists of work-in-progress throughout the country, throughout the world, to save the 
heartbreaking waste of years devoted to a project which someone else completes the day your own manuscript is finished. The more the movement for adult education grows roots, becoming a permanent feature of our national existence, the more demand there will be for listing, indexing, and abstracting motivated at the adult education level.

Understand that I don't care at this stage, who does what. Let small libraries, universities, colleges, research centers, government agencies, each do what they can and are specially fitted to do. But the work must be done, and it is the responsibility of the national library to voice the view that it should be done, supplying the lacks which others do not supply and taking priority on jobs that would suffer unless the greatest library in the world were behind them. If there is agreement on the principle that we ought to reach serious groups, interested in knowledge and in the long or short run influential in the character of opinion sustained in this democracy, a great many specific duties must follow. I am sure that many can be anticipated, but let me call attention to one project that I believe would be of great value to the efficiency with which work gets done by the federal agencies. Our Legislative Reference Service looks with favor upon the idea of routing to appropriate research and analysis groups in the different government departments and agencies, references to periodical literature appearing in every important country in the world. Only those who have worked inside a government agency during the war can understand the saving in time and the assurance of completeness of sources involved in this suggestion. Now this is in itself not a very difficult project, but it does involve distribution of material previously not distributed in this same constant and dependable way. And there are countless other services of this kind which can help to utilize the material the library possesses and is acquiring in constantly increasing adequacy.

\section{UNESCO: Center of International Bibliography}

History has been forced through its own growth to be generous with the race of bibliographers and in effect has bid us to prosper and multiply. To the historical conditions affecting the future of bibliography, I must now add the logical culmination-UNESCO's possibilities as an international center of bibliographical activity., In one sense the whole national, rationalized bibliographical program referred to throughout depends upon international bibliographical controls. Or, to put it more accurately, national controls and international controls are interdependent. Since UNESCO's activities will themselves be determined by what America and the other leading powers propose, I believe it is important for us to urge a most ambitious bibliographical program in the interests of intellectual progress and the interchange of the materials of knowledge and art. Probably no other historic epoch will be better suited to this undertaking than is the present one, for the grave lesions inflicted by the war have only highlighted the necessity for large-scale international exchange of information and promotion of cultural understanding.

I therefore believe that a number of longrange objectives for international bibliographical policy must be coupled with practical measures sympathetic to them. UNESCO must prepare to carry out a program ensuring equal access to all scholarly material, implemented by trade agreements providing among other things 
for freedom of these materials from export and import duties and currency controls. It should sponsor an international trade and document bibliography, composed largely of national bibliographies covering all publications for the country of origin, and national bibliographies of periodical literature. To aid scholarship in progress throughout the world, it might possibly find it desirable to create an international union catalog, based of course on catalogs of holdings by each nation. UNESCO should further provide for the exchange of bibliographical searching services and for the extensive and systematic international exchange of microfilm copies of publications.

The final provision that I consider highly significant for UNESCO's potential bibliographical activity is one which has been the subject of much planning and discussion on the national level in America; namely, the establishment of responsibility for the inclusive acquisition in designated subject fields. Although there are grave difficulties attendant upon the assignment of specific responsibility even on a national scale, it is obvious that the lines of national specialization must follow national interest and culture and that some kind of complementary assignment of responsibility must be introduced in order to maximize the pooled knowledge of the nations of the world.

\section{Will We Miss the Bus?}

I know these suggestions will involve in the years to come many men, many minds, and the almost endless patience required by group discussions and committee meetings. And, as I have pointed out, the specific modifications of some of my proposals and the forms in which they are to be implemented still remain to be worked out-I hope by the cooperation of libraries, scholars, and government agencies interested in this field. But I am convinced that we are historically at the crossroads of national maturity and know-how, and not only on an industrial, technological scale. We must act now, in the directions I have suggested, to control, extend, and exploit the fulness of the world's knowledge. Otherwise, we will find ourselves at some future day looking back with regret on the period when lack of historical imagination permitted bibliographical ventures to be sporadic private enterprises and individualistic struggles for recognition. We will be forced to realize that we flunked the challenge to cooperative problem-solving presented to us by the present historic juncture. What will there then be left to do but to shake our heads over our hapless folly and say in the words of our friends, the whole French people: "Si jeunesse savait, si vieillesse pouvait." 